\title{
PALM TOCOTRIENOLS CAUSE CLEAVAGE OF POLY-(ADP)-RIBOSE POLYMERASE ENZYME AND DOWN-REGULATION OF CYCLOOXYGENASE-2 PROTEIN LEVEL IN HUMAN BREAST CANCER CELLS
}

\section{RADHIKA LOGANATHAN*; KANGA RANI SELVADURAY*; KALANITHI NESARETNAM ${ }^{\star}$ and AMMU KUTTY RADHAKRISHNAN**}

\begin{abstract}
Breast cancer is a leading cause of cancer-related deaths in women globally. The anti-cancer effects of various forms of vitamin $E$ from palm oil [tocotrienol-rich fraction (TRF): natural form of vitamin E complex in palm oil, tocotrienol-enriched fraction (TEF), and major vitamin E homologues in palm oil: $\alpha$-tocopherol ( $\alpha$ Toc) and tocotrienols (T3) $(\alpha, \delta$ or $\gamma)$ ] were tested on two human breast cancer cell lines [MDA-MB-231 (triple negative) and MCF-7 (oestrogen-dependent)]. Chronic inflammation plays a key role in tumourigenesis. Both cell lines used express high levels of poly-(ADP)-ribose polymerase-1 (PARP-1) and cyclooxygenase-2 (COX-2), which are key mediators of inflammation. Tocotrienols exerted marked anti-proliferative by promoting apoptosis in both MDA-MB-231 and MCF-7 cells. In addition, T3 also induced time-dependent inactivation of PARP-1 as well as inhibited expression of COX-2 in both MDA-MB-231 and MCF-7 cells. The rate of T3 uptake was found to be comparable to the anti-proliferative and apoptotic activities observed. In conclusion, T3 induced marked anti-proliferative $(p<0.05)$ and pro-apoptotic $(p<0.05)$ effects, which were most likely associated with PARP-1 inactivation and COX-2 down-regulation in these human breast cancer cells.
\end{abstract}

Keywords: vitamin E, tocotrienol (T3), tocopherols (Toc), breast cancer, anti-inflammation, PARP-1, COX-2.

Received: 8 November 2019; Accepted: 1 July 2020; Published online: 7 October 2020.

\section{INTRODUCTION}

Breast and lung cancers are reported to be the leading cause of cancer-related deaths in women globally (World Health Organisation, 2018). Breast cancer $(\mathrm{BC})$ is the major cancer that affect women

\footnotetext{
Malaysian Palm Oil Board,

6 Persiaran Institusi, Bandar Baru Bangi,

43000 Kajang, Selangor, Malaysia.

** Jeffrey Cheah School of Medicine and Health Sciences, Monash University Malaysia,

47500 Bandar Sunway, Selangor, Malaysia.

E-mail: ammu.radhakrishnan@monash.edu
}

from diverse ethnic backgrounds all over the world (World Health Organisation, 2018). This is also the case in Malaysian women (Hisham and Yip, 2004); where 1:19 women is at risk of being diagnosed with BC (Lee et al., 2019). One of the widely acclaimed risk factors for BC are inherited genetic factors. It is not possible to change the genetic make-up of one at risk of developing cancer. However, studies have shown that only $10 \%-15 \%$ of $\mathrm{BC}$ incidence was related to heredity factors such as mutations in the BRCA1 and $B R C A 2$ genes (Kotsopoulos et al., 2014). This means that the majority of $\mathrm{BC}$ is attributed to non-genetic factors, which are mostly modifiable risk factors. 
Some of these non-genetic risk factors include reproductive factors such as exposure to endogenous and exogenous hormones or life-style factors such as alcohol consumption, overweight and obesity, and physical inactivity (World Health Organisation, 2018). So, it may be possible to prevent cancer by changing some of these modifiable risk factors. In this regard, it would benefit all of mankind if cancer can be prevented. It is always better to prevent onset of a disease rather than trying to find a cure once it sets in. Nutritional intervention could be one of the ways that can be used to achieve this goal.

Several natural bioactive compounds have been shown to possess anti-cancer activities, including tocotrienols (Aggarwal et al., 2019; Fu et al., 2019; Tung and $\mathrm{Ng}, 2019$ ), genistein (Zhang et al., 2019; Chae et al., 2019) and others (Cavalcanti et al., 2019). Consuming some of these bioactive compounds may be beneficial to reduce risk of cancer and its mortality rate. Vitamin E exists naturally as two families namely, tocopherols (Toc) and tocotrienols (T3). Each vitamin E family exists naturally in four isoforms namely alpha $(\alpha)$, beta $(\beta)$, delta $(\delta)$ and gamma $(\gamma)$. Palm oil is a rich source of vitamin E. Vitamin E in palm oil is known as tocotrienol-rich fraction (TRF). The main vitamin $\mathrm{E}$ isoforms present in palm oil are $\gamma \mathrm{T} 3(46 \%), \alpha \mathrm{Toc}(20 \%), \delta \mathrm{T} 3(22 \%)$ and $\beta \mathrm{T} 3$ (12\%) (Loganathan et al., 2013). Tocotrienols are structurally similar to Toc, except that the side-chain of T3 have three unsaturated bonds and one chiral centre, which are reported to be key enablers that allow T3 to enter tissues lipids freely and perform more efficient metabolic functions compared to Toc (Ahsan et al., 2014). Palm TRF has met the standard of reasonable certainty of no harm and thus is considered safe within the terms of the American Federal Food, Drug and Cosmetic Act and has been given the Generally Recognised as Safe (GRAS) status (US Food and Drug Administration, 2009). There is now compelling evidence, which shows that vitamin E, especially T3 have several healthenhancing effects such as antioxidant (Aggarwal et al., 2019; Fu et al., 2019; Tung and Ng, 2019), antiinflammatory (Yang and Jiang, 2019), anti-obesity (Fukui et al., 2019) and anti-cancer (Montagnani Marelli et al., 2019).

Poly-(ADP)-ribose polymerase-1 (PARP-1) is an enzyme reported to play an important role in several cellular processes involving deoxyribonucleic acid (DNA) repair and programmed cell death (Pinto et al., 2009). Breast cancer cells are reported to express high levels of PARP-1 (Ma et al., 2019). Cleavage of PARP-1 is shown to reduce inflammatory responses as well as induce apoptosis, which is mediated through activation of caspases (Ma et al., 2019). When apoptosis is initiated, PARP-1 is activated when it binds to DNA ends or nicks; and subsequently gets inactivated following its cleavage. Cleavage of nuclear PARP occurs through activation of caspases, which cleave between Asp 216 and Gly 217, separating the $116 \mathrm{kDa}$ PARP protein into one large $(90 \mathrm{kDa})$ and one small $(26$ $\mathrm{kDa}$ ) fragments (Satoh et al., 2003). The smaller fragment contains a zinc finger motif essential for DNA binding; whilst the larger fragment has the auto-modification and catalytic domains (Satoh et al., 2003). Cleavage of PARP prevents depletion of energy by nicotinamide adenine dinucleotide (NAD) and adenosine triphosphate (ATP), which is reported to be required for later stages of apoptosis (Satoh et al., 2003).

Many human cancers exhibit elevated prostaglandin (PG) levels owing to up-regulation of cyclooxgense-2 (COX-2). The COX-2 levels are reported to be elevated in about $40 \%$ of aggressive $\mathrm{BC}$ cases; with a higher incidence in pre-invasive ductal carcinoma in situ (Howe, 2007). Elevated levels of COX-2 in BC inhibit apoptosis, enhance angiogenesis; increase invasiveness; promote cell growth and produce mutagens (Divvela et al., 2010). The COX-2-prostaglandin E2 (PGE2) pathway is reported to play an important role in helping cancer cells adapt to the tumour microenvironment (Divvela et al., 2010) such as becoming resistant to programmed cell death. Non-steroidal antiinflammatory drugs (NSAID), which are COX-2 inhibitors, are often prescribed to relief pain, fever and inflammation (Jahnavi et al., 2019).

The present study was conducted to compare the effects of various forms of vitamin $\mathrm{E}$ from palm oil on the effects on PARP-1 cleavage and COX-2 inhibition using two human breast cancer cell lines namely MDA-MB-231 (triple negative) and MCF-7 (oestrogen-dependent).

\section{MATERIALS AND METHODS}

\section{Preparation of Vitamin E Treatments}

$\operatorname{TRF}[\gamma \mathrm{T} 3(29 \%) ; \alpha \operatorname{Toc}(32 \%) ; \alpha \mathrm{T} 3(25 \%) ; \delta \mathrm{T} 3(14 \%)]$ (Golden Hope Plantations Bhd, Selangor, Malaysia); tocotrienol-enriched fraction (TEF), which is enriched with tocotrienols [ $\alpha \mathrm{T} 3(45.3 \%)$; $\delta \mathrm{T} 3(25.3 \%)$; $\gamma \mathrm{T} 3(29.4 \%)]$ and free from $\alpha$ Toc (Davos Life Sciences Pte Ltd, Singapore); pure T3 isoforms ( $\alpha \mathrm{T} 3, \delta \mathrm{T} 3$ and $\gamma$ T3) (Eisai Food and Chemicals Co., Ltd, Tokyo, Japan) and $\alpha$ Toc (Aldrich Chemical Company, Inc., Milwaukee, USA). The T3 preparations $\left(10 \mu \mathrm{g} \mathrm{ml}^{-1}\right)$ used for the various assays were quantified using high-performance liquid chromatography (HPLC).

\section{Cell Lines}

It has been shown previously that $\mathrm{T} 3$ selectively inhibit proliferation of cancer cells (Loganathan et al., 2013; 2015) but not normal cells. To further demonstrate that T3 are safe for normal cells, 
the effect of culturing murine splenocytes in the presence of serial concentrations of different isoforms of vitamin E was also examined. Briefly, spleen was aseptically removed from six-week old female albino (BALB/c) mice and placed in a sterile Petri dish $(10 \mathrm{~cm})$ containing $10 \mathrm{ml}$ of ice-cold complete Roswell Park Memorial Institute medium (RPMI 1640): fetal bovine serum (FBS): L-glutamine: penicillin-streptomycin at 97:5:1:1 ratio. Splenocytes were released by gently teasing out the spleen and recovered via centrifugation at $4000 \mathrm{rpm}$ for $10 \mathrm{~min}$. The cells were resuspended in complete medium at $1 \times 10^{6} \mathrm{cells} \mathrm{ml}^{-1}$ and $100 \mu \mathrm{l}$ per well was added to a 96-well plate. Cells were left at $37^{\circ} \mathrm{C}$ in a humidified $5 \% \mathrm{CO}_{2}$ incubator for $1 \mathrm{hr}$ prior to treatment. Upon cell culture stabilisation, vitamin E treatments (0-10 $\mu \mathrm{g} \mathrm{ml}^{-1}$ ) were added and the cells were incubated in a humidified atmosphere of $5 \% \mathrm{CO}_{2}$ in air at $37^{\circ} \mathrm{C}$ for $24 \mathrm{hr}$. Untreated splenocytes served as negative control whilst lipopolysaccharides (LPS) (Sigma Aldrich, USA) stimulated murine splenocytes were used as positive controls.

The highly aggressive triple negative human breast cancer cells, MDA-MB-231 and oestrogendependent human breast cancer cells, MCF-7 were obtained from the American Type Culture Collection (ATCC) (ATCC, Manassas, Virginia, USA). The MDA-MB-231 cells were cultured as monolayer in culture flasks (Orange Scientific, USA) in Dulbecco's Modified Eagle Medium (DMEM) supplemented FBS, L-glutamine: penicillin-streptomycin at 88:10:1:1 ratio. The cells were maintained at $37^{\circ} \mathrm{C}$ in a humidified atmosphere of $5 \% \mathrm{CO}_{2}$ incubator. The MCF-7 cells were grown using the same condition and medium except that $10^{-8} \mathrm{M}$ of $\beta$-oestradiol was also added to the medium. The culture medium was changed routinely every alternate day.

\section{Cell Proliferation Assay}

The MTT assay (Chemicon International Inc., USA) was conducted to measure cell viability. Briefly, $10 \mu \mathrm{l}$ of the MTT solution was added to all wells and incubated for $4 \mathrm{hr}$ at $37^{\circ} \mathrm{C}$. Then, $100 \mu \mathrm{l}$ of $4 \mathrm{mM}$ $\mathrm{HCl}$-acid isopropanol stop mixture was added into each well, shaken on orbital shaker for $15 \mathrm{~min}$ and mixed thoroughly by pipetting the liquid to dissolve the black formazan, which results in a homogeneous blue solution. Absorbance at $570 \mathrm{nM}$ was measured on microplate reader (Sunnyvale, USA).

\section{Cell Death Detection-DNA Fragmentation Assay}

The cells were seeded at a density of $1 \times 10^{4}$ cells / well and incubated for $1 \mathrm{hr}$ at $37^{\circ} \mathrm{C}$ in a humidified atmosphere of $5 \% \mathrm{CO}_{2}$. Following this, $100 \mu \mathrm{l}$ of the test compounds at desired concentrations, positive control, and control with and without vehicle were added to the respective wells. The plate was incubated in the incubator for the specified period of time ( $6 \mathrm{hr}, 15 \mathrm{hr}, 24 \mathrm{hr}$ or $48 \mathrm{hr}$ ). At the end of each incubation period, cytoplasmic and nuclear histone/DNA fragments from cells were extracted and quantified using a commercial cell death detection kit (Roche Diagnostic Gmbh, Mannheim, Germany). The principle of this assay is based on sandwich-enzyme-immunosorbent whereby mouse monoclonal antibodies are directed against DNA and histones, respectively. Briefly, the nuclear and cytoplasmic fractions were incubated in a streptavidin-coated plate that was provided with the kit. Subsequently, an immunereagent containing biotin-labelled anti-histonebiotin peroxidase conjugated anti-DNA-POD was added for the detection of histone-associated DNA fragments. Colour change, indicating binding was detected following the addition of ABTS, which is the substrate for the peroxidase. Spectrometric absorbance at $405 \mathrm{nM}$ was measured. The results are presented as enrichment factor of mono and oligonucleosomes as described previously (Loganathan et al., 2013; 2015).

\section{COX-2 Protein Concentration}

The amount of COX-2 expressed in the human breast cancer cells (MCF-7 or MDA-MB-231 cells) treated with various forms of vitamin $\mathrm{E}$ was analysed using a commercial human COX-2 enzyme-linked immunosorbent assay (ELISA) kit. Briefly, the human breast cancer cells were seeded at a density of $1 \mathrm{x}$ $10^{7}$ in $10 \mathrm{~cm}$ Petri dishes. The cells were pre-treated with various forms of vitamin E $\left(10 \mu \mathrm{g} \mathrm{ml}^{-1}\right)$ for 24 hr or $48 \mathrm{hr}$ at $37^{\circ} \mathrm{C}$ in a humidified $5 \% \mathrm{CO}_{2}$ incubator. Following this, the cells were exposed to $1 \mathrm{nM}$ of tumour necrosis factor-alpha (TNF-alpha) for 30 min. Untreated cells served as control. At the end of the incubation period, the cells were harvested, and a cell lysate was prepared as previously described (Loganathan et al., 2015). Protein content in the cell lysate was estimated by DC protein assay (Bio-Rad Laboratories). The amount of COX-2 in the cell lysate samples was quantified using a commercial human COX-2 ELISA kit as recommended by the manufacturer (Alpha Diagnostic International, USA). Briefly, the cell lysates were incubated for $1 \mathrm{hr}$ with mouse monoclonal antibody coated plate. Following subsequent wash, horseradishperoxidase (HRP)-conjugated antibody against COX-2 was added to the wells. The plate was left at room temperature for half an hour before addition of the 3,3',5,5'-Tetramethylbenzidine (TMB) substrate. The solution turned yellow once the stop solution was added to the wells. Absorbance at $450 \mathrm{nM}$ of the samples were measured. The concentration of COX2 in each cell lysate sample was generated based on the standard curve and calculated based on protein concentration. 


\section{Determination of PARP Cleavage}

The amount of PARP cleavage induced in the human breast cancer cells (MCF-7 or MDA-MB-231 cells) treated with various forms of vitamin $\mathrm{E}$ was analysed using a commercial human PARP cleavage ELISA kit. Briefly, the human breast cancer cells were seeded at a density of $1 \times 10^{7}$ in $10 \mathrm{~cm}$ Petri dishes. The cells were pre-treated with various forms of vitamin $\mathrm{E}\left(10 \mu \mathrm{g} \mathrm{ml}^{-1}\right)$ for $6 \mathrm{hr}$, $15 \mathrm{hr}, 24 \mathrm{hr}$ and $48 \mathrm{hr}$ at $37^{\circ} \mathrm{C}$ in a humidified $5 \% \mathrm{CO}_{2}$ incubator. Following this, the cells were exposed to $1 \mathrm{nM}$ of TNF-alpha for $30 \mathrm{~min}$. Untreated cells served as control. At the end of the incubation period, the cells were harvested, and a cell lysate was prepared. The amount of cleaved PARP (Asp214) in the cell lysate samples was quantified using a commercial human cleaved PARP (Asp214) ELISA kit using the manufacturer (PathScan, Cell Signalling Technology Inc.) recommended protocol as described previously (Loganathan et al., 2013; 2015).

\section{Vitamin E Cellular Accumulation Analysis}

Cellular accumulation of vitamin E was determined according to published protocols (Sen et al., 2000) with some modifications. Briefly, the human breast cancer cells (MCF-7 or MDA-MB-231 cells) were treated with vitamin $\mathrm{E}\left(10 \mu \mathrm{g} \mathrm{ml}^{-1}\right)$ for 72 $\mathrm{hr}$. Following this, the cells were washed twice with cold phosphate-buffered saline (PBS) and subjected to a trysinisation step. The cells were recovered by centrifugation. The cell pellet was dried under nitrogen gas to estimate the dry weight. Then, 0.925 $\mathrm{ml}$ of PBS containing $1 \mathrm{mM}$ EDTA disodium salt, $0.025 \mathrm{ml}$ of $10 \mathrm{mg} \mathrm{ml}^{-1}$ butylated hydroxytoluene, and $0.5 \mathrm{ml}$ of $0.1 \mathrm{M}$ sodium dodecyl sulphate (SDS) was added to the dry pellet. This was followed by addition of $1 \mathrm{ml}$ ethanol and $5 \mathrm{ml}$ hexane. The mixture was vigorously vortexed for $1 \mathrm{hr}$ and centrifuged at $3000 \mathrm{~g}$ for $15 \mathrm{~min}$. The hexane layer was used for analysis with the HPLC. Quantification and characterisation of the various forms of vitamin $\mathrm{E}$ were done using a normal phase HPLC equipped with fluorescence spectrophotometer (HP Agilent 1100 HPLC G1321A FLD Detector, USA) and ChemStation Rev. A.06.0x (Agilent, USA). The mobile phase consisted of $970 \mu$ l hexane; $25 \mu \mathrm{l}$ dioxane and $5 \mu \mathrm{l}$ isopropyl alcohol $(\mathrm{v} / \mathrm{v})$. The mobile phase was delivered at $1 \mu \mathrm{min}^{-1}$ flow rate through a silica column [Phenomenex ${ }^{\circledR}$ Luna $5 \mathrm{~m}$ silica column (dimension: $250 \times 4.6 \mathrm{~mm}$ I.D, 5 $\mu \mathrm{M})]$. A standard solution of $10 \mu \mathrm{g} \mathrm{ml}^{-1}$ vitamin $\mathrm{E}$ was injected prior to sample injection for calibration purposes. Fluorescence detector was set at emission $(\lambda \mathrm{em}=325 \mathrm{~nm})$ and excitation $(\lambda \mathrm{ex}=295 \mathrm{~nm})$ spectra. The samples were then injected onto HPLC and analysed with Agilent Chemstation in duplicates.
Equation:

$\begin{gathered}\text { Percentage of } \\ \text { uptake }(\%)\end{gathered}=\begin{gathered}\text { Concentration of vitamin } \mathrm{E} \\ \text { in cells } / \text { media } \times 100\end{gathered}$

\section{Statistical Analysis}

Data were expressed as the average of mean \pm standard deviation of triplicates. Experimental data were processed by one-way analysis of variance (ANOVA) test Tukey HSD post-hoc test were used to compare treatment means. The P-value of $<0.05$ was considered statistically significant.

\section{RESULTS}

\section{Effects of Palm Vitamin E on Normal Cells}

None of the vitamin E treatments at 0-10 $\mu \mathrm{g}$ $\mathrm{ml}^{-1}$ concentrations inhibited proliferation of the lipopolysaccharide (LPS)-stimulated murine splenocytes (Figure 1). In fact, treatments with $\alpha \mathrm{T} 3, \delta \mathrm{T} 3$ or $\gamma \mathrm{T} 3$ at $1 \mu \mathrm{g} \mathrm{ml}^{-1}$ significantly $(\mathrm{P}<0.05)$ increased viability of the murine splenocytes. Similar results were observed when higher concentrations of these vitamin $\mathrm{E}$ isoforms were used. The findings imply that T3 may have less impact on the proliferation of normal cells. In order to confirm that T3 isoforms are not cytotoxic to normal cells, the LPS-stimulated murine splenocytes were treated with a fixed concentration of $10 \mu \mathrm{g} \mathrm{ml}^{-1}$ of various forms of vitamin E. The cytoplasmic and nuclear histone/DNA fragments from these cells were harvested and analysed using a cell death ELISA kit. The concentration chosen was previously shown to induce apoptosis in human breast cancer cells (Loganathan et al., 2013). None of the test compounds showed any signs of inducing apoptosis in the murine splenocytes (Figure 2). These findings showed that $\mathrm{T} 3$ isoforms did not have cytotoxic effects on the murine splenocytes, i.e. normal primary cells.

\section{Induction of Apoptosis Due to Down-regulation of COX-2}

Protein concentration of COX-2 was downregulated in MDA-MB-231 (Figure 3a) and MCF7 (Figure 3b) human breast cancer cells following treatment with tocotrienols. In control cells, the concentration of COX-2 was elevated in both human breast cancer cells, even before the addition of TNFalpha (Figure 3). The results showed that tocotrienols caused significant $(\mathrm{P}<0.05)$ reduction in protein concentration of COX-2 in the human breast cancer cells. The ability of the vitamin $\mathrm{E}$ isomers to reduce COX-2 expression in the MDA-MB-231 after $24 \mathrm{hr}$ was found to be higher when compared to $48 \mathrm{hr}$. A similar trend was observed with the MCF-7 cells. 


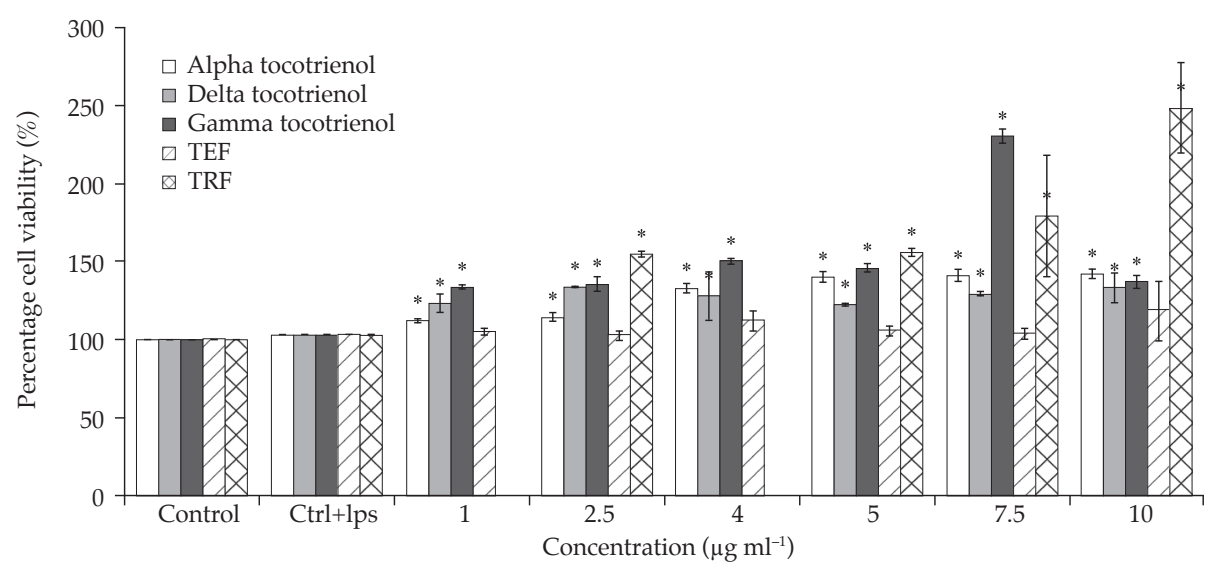

Note: There are no data available for tocotrienol-rich fraction (TRF) at $1 \mu \mathrm{g}$ and $4 \mu \mathrm{g} \mathrm{ml}^{-1}$ as these concentrations were not tested.

TEF - tocotrienol-enriched fraction.

SD - standard deviation.

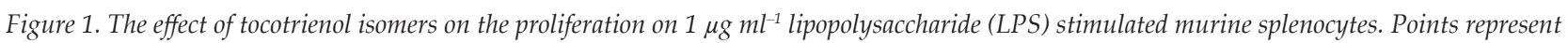
the mean of three readings/well $\pm S D$ for triplicates in each treatment group are shown. ${ }^{*} P<0.05$ compared with control group.

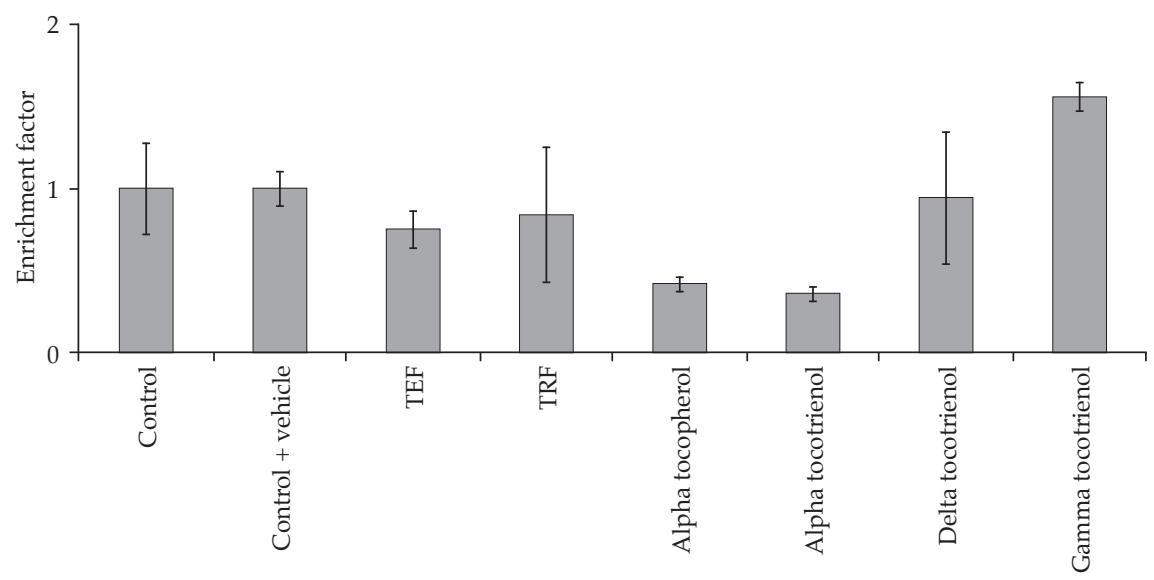

Note: TRF - tocotrienol-rich fraction.

TEF - tocotrienol-enriched fraction.

SD - standard deviation.

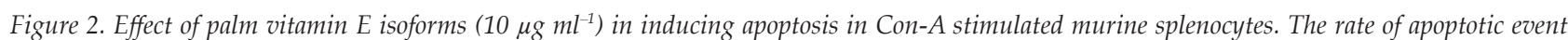
is presented as the enrichment factor. Points represent the mean of three readings/well $\pm S D$ for triplicates in each treatment group are shown. No significant difference compared to control.

a) MDA-MB-231 cells

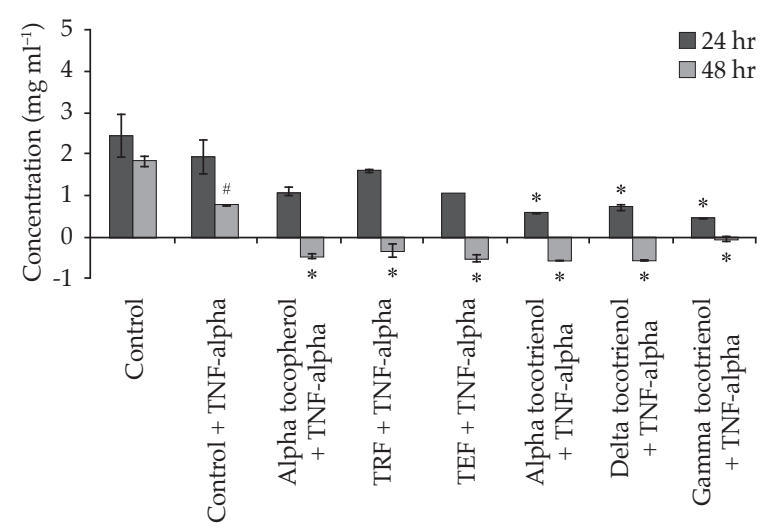

b) MCF-7 cells

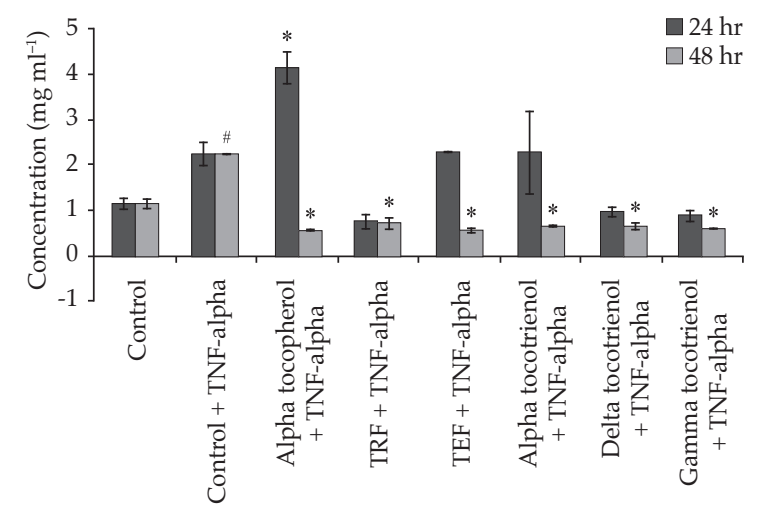

Note: TNF - tumour necrosis factor.

Figure 3. The effect of tocotrienol isomers on cyclooxygenase-2 (COX-2) expression of 1 nM TNF-alpha stimulated (a) MDA-MB-231 and (b) MCF-7 human breast cancer cells for $24 \mathrm{hr}$ or $48 \mathrm{hr}$. Points represent the mean $\pm S D$ for triplicates in each treatment group are shown. ${ }^{*}$ Values are significantly different $(p<0.05)$ from control group. *Values are significantly different $(p<0.05)$ from control + TNF-alpha group. 


\section{Induction of Apoptosis Due to PARP Cleavage}

The MDA-MB-231 (Figure 4a) and MCF-7 (Figure $4 b$ ) were treated with the various forms of $10 \mu \mathrm{g} \mathrm{ml}^{-1}$ palm vitamin $\mathrm{E}$ and PARP cleavage activity was determined over a period of time at fixed intervals. The percentage of PARP cleavage was generally not detectable after $6 \mathrm{hr}$ and $15 \mathrm{hr}$ of exposure to the palm vitamin $\mathrm{E}$ in (a) MDA-MB-231 (Figure $4 a$ ) or (b) MCF-7 (Figure 4b) human breast cancer cells. This period corresponds to the PARP activation stage. However, the percentage of PARP cleavage increased $(\mathrm{P}<0.05)$ when the exposure period to vitamin $\mathrm{E}$ was increased to $24 \mathrm{hr}$ and $48 \mathrm{hr}$, indicating PARP inactivation in both (a) MDA-MB-231 (Figure 4a) or (b) MCF-7 (Figure 4b) human breast cancer cells. The findings show a time-dependent cleavage of PARP with treatments with all forms of palm vitamin E on both the cell lines except for $\alpha$-tocopherol on the MCF-7 cells (Figure 4b).

\section{Cellular Uptake of Vitamin E}

Cellular accumulation of vitamin E should be demonstrated in order to compare cellular affinity, bioavailability and physiological concentrations. The results show that cellular uptake of T3 isoforms were more efficient than $\alpha$ Toc in both the human breast cancer cell lines (MCF-7 and MDA-MB-231). The uptake of vitamin $\mathrm{E}$ isoforms decreased in the following order: $\alpha \mathrm{T} 3>\mathrm{TEF}>\delta \mathrm{T} 3>\mathrm{TRF}>\gamma \mathrm{T} 3>$ $\alpha$ Toc in MDA-MB-231 cells whilst in MCF-7 cells, the order was $\alpha \mathrm{T} 3>\delta \mathrm{T} 3>\gamma \mathrm{T} 3>\mathrm{TEF}>\mathrm{TRF}>\alpha \mathrm{Toc}$ (Figure 5). a) MDA-MB-231 cells

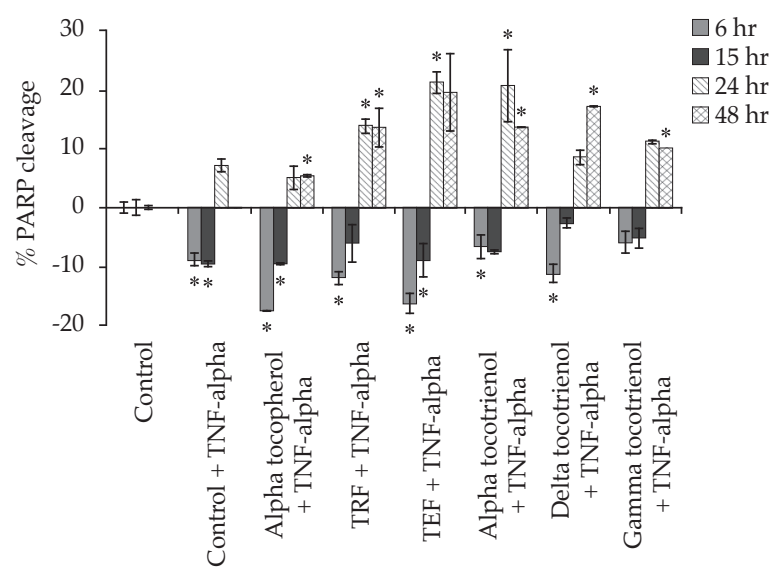

b) MCF-7 cells

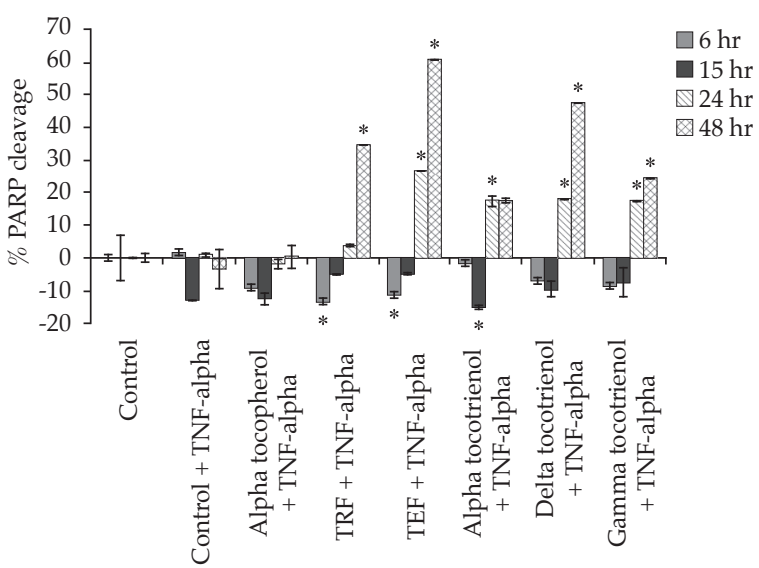

Note: TNF - tumour necrosis factor.

SD - standard deviation.

Figure 4. Apoptosis induction by poly-(ADP)-ribose polymerase (PARP) cleavage in time-dependent manner following vitamin E treatment on a) MDA-MB-231 and b) MCF-7 cells. Points represent the mean \pm SD for triplicates in each treatment group are shown. *Values are significantly different $(p<0.05)$ from control $+T N F$-alpha group.

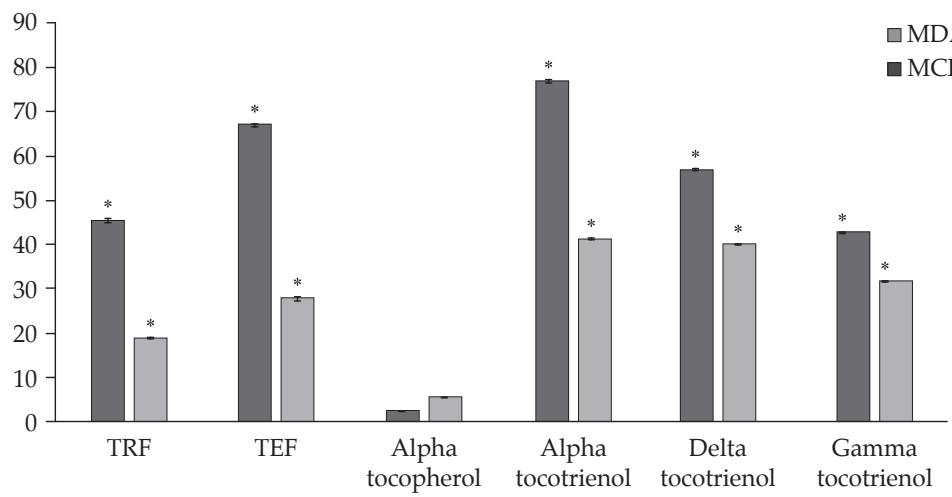

Note: TRF - tocotrienol-rich fraction.

TEF - tocotrienol-enriched fraction.

SD - standard deviation.

ANOVA - analysis of variance.

Figure 5. Cellular uptake of palm vitamin E. Results are shown as the mean $\pm S D$ from duplicate cultures.

*Values are significantly different $(p<0.05)$ from alpha tocopherol group (one-way ANOVA). 


\section{DISCUSSION}

Current study shows T3 induced selective antiproliferative and pro-apoptotic effects, which were most likely associated with PARP-1 inactivation and COX-2 down-regulation in MDA-MB-231 and MCF-7 human breast cancer cells.

TRF was used in most of the initial studies involving palm T3. This bioactive compound has a standardised composition of 32\% $\alpha \mathrm{Toc}, 25 \% \alpha \mathrm{T} 3$, $29 \% \gamma \mathrm{T} 3$, and $14 \% \delta \mathrm{T} 3$. This has raised certain queries regarding the effect of $\alpha$ Toc in the observed response. So, the efficacy of TRF, T3 isoforms $(\alpha, \delta$ and $\gamma$ ), $\alpha$ Toc as well as TEF was compared in this study. The TEF is a tocopherol-free preparation of TRF, which contains a $\alpha-, \delta$ - and $\gamma$-tocotrienols.

Based on our previous growth inhibition studies and $\mathrm{IC}_{50}$ values, the anti-proliferative activity of vitamin $\mathrm{E}$ on the MDA-MB-231 cells was found to reduce in the following order: TEF $\left(3.7 \mu \mathrm{g} \mathrm{ml}^{-1}\right)>$ $\gamma \mathrm{T} 3\left(4.7 \pm 0.8 \mu \mathrm{g} \mathrm{ml}^{-1}\right)>\delta \mathrm{T} 3\left(6.9 \pm 0.3 \mu \mathrm{g} \mathrm{ml}^{-1}\right)>\mathrm{TRF}$ $\left(8.5 \pm 0.2 \mu \mathrm{g} \mathrm{ml}^{-1}\right)>\alpha \mathrm{T} 3\left(9.6 \pm 1.1 \mu \mathrm{g} \mathrm{ml}^{-1}\right)$ whilst for MCF-7 cells, it reduced as: TEF $\left(3.4 \pm 0.2 \mu \mathrm{g} \mathrm{ml}^{-1}\right)$ $>\operatorname{TRF}\left(4.55 \pm 0.7 \mu \mathrm{g} \mathrm{ml}^{-1}\right)>\gamma \mathrm{T} 3\left(6.35 \pm 0.15 \mu \mathrm{g} \mathrm{ml}^{-1}\right)$ $>\delta \mathrm{T} 3\left(6.8 \pm 0.3 \mathrm{mg} \mathrm{ml}^{-1}\right)>\alpha \mathrm{T} 3\left(11.05 \pm 0.45 \mu \mathrm{g} \mathrm{ml}^{-1}\right)$. In contrast, no inhibition of cell proliferation was reported on $\alpha$ Toc concentrations tested $\left(0-20 \mu \mathrm{g} \mathrm{ml}^{-1}\right)$ (Loganathan et al., 2013). In the current study, we found no adverse effects on normal LPS-stimulated murine splenocytes with similar test compounds. Hence, the data confirms that T3 exert selective anti-proliferative effects on breast cancer cells without any adverse effect on normal cells at the concentrations tested $\left(0-10 \mu \mathrm{g} \mathrm{ml}^{-1}\right)$.

Induction of apoptosis is one of the most potent defence against progression of cancer. Hence, many of the currently used chemotherapeutic drugs are developed to target apoptotic cell death (Ricci and Zong, 2006). However, a key stumbling block of many of these anti-cancer drugs is that many of these drugs can also damage normal cells. Thus, novel molecules that can selectively induce apoptosis in cancer cells whilst sparing normal cells would be a preferred approach for cancer treatment. Several studies have confirmed that T3 selectively induce apoptosis in cancer cells but do not affect normal cells (McIntyre et al., 2000a). The results from the present study reaffirms that $\mathrm{T} 3$ selectively target cancer cells and exerted no or little toxicity.

Increased levels of COX-2 have been reported in aggressive breast cancers (Howe, 2007). Elevated levels of COX-2 could result in certain kinds of cancer cells becoming resistant to programmed cell death mostly due to the impaired ability of the cell to undergo intrinsic cell death. In the present study, the protein concentration of COX-2 was down-regulated following treatment with T3. This is an important observation as COX-2 is a
NF-кB regulated gene product associated with cell proliferation. This effect was also observed in both the human breast cancer cell that were pre-treated with various forms of vitamin $\mathrm{E}\left(10 \mu \mathrm{g} \mathrm{ml}^{-1}\right)$ for 24 $\mathrm{hr}$ before these cells were exposed to $1 \mathrm{nM}$ of TNFalpha for $30 \mathrm{~min}$. As shown in Figure 3, the protein concentration of COX-2 was elevated in both the human breast cancer cells that were not subjected to pre-treatment with the vitamin $\mathrm{E}$ isomers prior to exposure to the TNF-alpha. The results showed that tocotrienols significantly $(\mathrm{p}<0.05)$ reduced the protein concentration of COX-2 in these cells. The ability of the vitamin $\mathrm{E}$ isomers to reduce protein concentration of COX-2 in the MDA-MB-231 was in the following order $\gamma \mathrm{T} 3>\alpha \mathrm{T} 3>\delta \mathrm{T} 3>\mathrm{TEF}>$ $\alpha \mathrm{Toc}>\mathrm{TRF}$ and in the following order: TRF $>\gamma \mathrm{T} 3$ $>\delta \mathrm{T} 3$ for MCF-7 cells. This finding is based on the concentration of COX-2 following $24 \mathrm{hr}$ of pretreatment. TEF and $\alpha \mathrm{T} 3$ required more than $24 \mathrm{hr}$ to reduce protein concentration of COX-2 in the MCF-7 cell lines. When the cells were pre-treated with the vitamin $\mathrm{E}$ isomers for $48 \mathrm{hr}$, the ability of the vitamin $\mathrm{E}$ isomers to reduce protein concentration of COX-2 in the MDA-MB-231 reduces in the following order $\alpha \mathrm{T} 3>\delta \mathrm{T} 3>\mathrm{TEF}>\alpha \mathrm{Toc}>\mathrm{TRF}>\gamma \mathrm{T} 3$ and in the following order TEF $>\alpha \mathrm{Toc}>\gamma \mathrm{T} 3>\alpha \mathrm{T} 3>\delta \mathrm{T} 3>\mathrm{TRF}$ for MCF-7 cells.

Chronic inflammation plays a role in several steps associated with tumourigenesis; such as cellular transformation, promotion, survival, proliferation, invasion, angiogenesis and metastasis. Besides cancer, chronic inflammation also contributes to development of many degenerative disorders like cardiovascular diseases, neurogenerative disorders, arthritis and diabetes. Knocking down inflammation or inhibiting COX-2 are good targets for anti-cancer treatments (Jahnavi et al., 2019). NSAID are commonly prescribed drugs that act as COX inhibitors, which are commonly used to relief pain, fever and inflammation (Jahnavi et al., 2019). Vitamin E, especially T3 have potent free radical scavenging activities and thus could serve as anti-inflammatory therapeutic agent. Synergism between low concentrations of $\gamma \mathrm{T} 3$ and celecoxib was reported to induce growth inhibition, which was associated with a decrease in $\mathrm{PGE}_{2}$ synthesis, COX-2, phospho-Akt (active), and phospho-NF-кВ (active) levels in breast cancer patients while avoiding the toxicity associates with high-dose COX-2 inhibitor monotherapy (Shirode and Sylvester, 2010). The mechanisms underlying the potent anti-inflammatory activity of TRF observed on LPS-induced human monocytes have been attributed to inhibition of iNOS, COX2 and NF-кB but not inhibition of COX-1 (Wu et al., 2008). Dietary $\gamma \mathrm{T} 3$ was reported to inhibit COX-2 activity in LPS-activated macrophages and IL-1 $\beta$-stimulated human epithelial cells (Wu et al., 2008). 
Tocotrienols appear to be better antiinflammatory agents when compared to $\alpha$ Toc; and the most effective form was reported to be $\delta \mathrm{T} 3$ in LPS-stimulated RAW264.7 macrophages (Yam et al., 2009). Current results indicate that T3 can downregulate protein concentration of COX-2 on both human breast cancer cell lines (MCF-7 and MDAMB-231) in a time-dependent manner (Figure 3).

PARP-1 inhibitors are proteins that plays a major role in a number of cellular processes involving mainly DNA repair and programmed cell death (Pinto et al., 2009). Cleavage of PARP proteins indicate presence of an apoptotic event. This was the principle applied in the commercial ELISA kit used in this study; where the kit detected the cleaved fragment $(89 \mathrm{kDa})$ that consisted mainly of the catalytic domain of PARP. The PARP molecule is a protein involved in a number of cellular processes involving mainly DNA repair and NF$\mathrm{\kappa B}$ is one of its acceptor proteins. Majority of breast carcinomas were found to express high level of PARP-1 (Domagala et al., 2011). Both cell lines used in the present study (MCF-7 and MDA-MB-231) are aggressive human breast cancer cell lines that express high levels of PARP-1, which enable these cells to recruit and induce activation of NF-кB; a protein that is closely related to inflammation and upregulation of COX-2. Our results show that the expression of PARP-1 (Figure 4) and protein concentration of COX-2 (Figure 3) were downregulated in both human breast cancer cells (MCF-7 and MDA-MB-231) treated with T3. Hence, a dual role of apoptosis and anti-inflammation could be observed with T3 treatment. Previously, we have reported that the pro-apoptotic effects of T3 was associated with DNA fragmentation and PARP-1 cleavage (Loganathan et al., 2013).

In this article, we report the mechanism of PARP-1 cleavage. In the event of apoptosis cleavage of the nuclear PARP-1 occurs through a cascade of caspases between Asp 216 and Gly 217 separating the $116 \mathrm{kDa}$ PARP-1 protein into two fragments of $26 \mathrm{kDa}$ and $90 \mathrm{kDa}$. Activation of PARP-1 was found at 6-15 $\mathrm{hr}$ corresponding to its binding to DNA ends or nicks; and subsequently the inactivation of PARP-1 occurs by its cleavage at 24-48 hr (Figure 5). In human, tocotrienols possess a halflife of $3.5 \mathrm{hr}$ and its clearance from hepatic blood flow is within $24 \mathrm{hr}$ (Aggarwal et al., 2010), this article may provide a benchmark of $24 \mathrm{hr}$ to study apoptotic activity of tocotrienols. Besides, it is also evident cleavage of PARP-1 reduces inflammatory responses and cell death mediated by apoptosis. The cleavage of PARP-1 prevents the induction of necrosis during apoptosis and ensures appropriate execution of caspase-mediated programmed cell death. It is evident as previously we have shown that the apoptotic death by DNA fragmentation were notably higher compared to necrotic death with tocotrienols treatment (Loganathan et al., 2013).

The level of saturated phytyl chain and methylated chromanol ring in T3 may influence its mobility and distribution into the cells, thereby reflecting its biopotency (Palozza et al., 2006). There are various evidence to support the potent free radical scavenging activity of T3; including biochemical reactions towards radicals as well as cellular uptake or distribution, concentration and mobility at the microenvironment (Yoshida et al., 2003). It was reported that $\alpha \mathrm{T} 3$ was better incorporated in human erythrocytes when compared to $\alpha$ Toc and it resulted in providing better protection against oxidation and deformability (Begum and Terao, 2002). Tocotrienols uptake was reported to be more efficient than $\alpha$ Toc in HT4 neuron cells in culture (Sen et al., 2000).

According to McIntyre et al. (2000a, b), T3 displayed significantly higher bio-potency than Toc as these are more easily or preferentially taken up by normal, pre-neoplastic (CL-SI), neoplastic (-SA) and highly malignant (+SA) mammary epithelial cells (McIntyre et al., 2000a, b). Twenty-four times greater concentration of $\alpha, \gamma$ and $\delta$ Toc was required to attain similar concentration of $\alpha, \gamma$ and $\delta \mathrm{T} 3$ in the pre-neoplastic and neoplastic mammary epithelial cell lines. Interestingly, in primary cultures it was found that the rate of uptake of vitamin $\mathrm{E}$ isoforms was significantly higher in tumour cells as compared to normal mammary epithelial cells. McIntyre et al. (2000a) reported the order of cellular accumulation of T3 in mammary epithelial to be as $\delta \mathrm{T} 3>\gamma \mathrm{T} 3>$ $\alpha \mathrm{T} 3$; which appeared to have a direct correlation between relative bio-potency and observed effects. Decrease in the level of chromanol ring methylation $(\alpha>\gamma>\delta)$ also corresponds to a decrease in partition coefficient of the compound. This causes a reduction in lipophilicity; thus, enhances cellular accumulation (McIntyre et al., 2000a). The finding from the present study also implies that $\alpha \mathrm{T} 3$ is best absorbed by the cells, which corresponds to our previous report on the apoptotic activity of vitamin E from palm oil (Loganathan et al., 2013). The preferential uptake of T3 can somewhat explain the reasons behind the higher anti-cancer bio-potency of T3 when compared to $\alpha$ Toc.

Status of estrogen receptor (ER) is an important factor to be considered for the prognosis of cancer (Nesaretnam et al., 2012). ER-beta (ER- $\beta$ ) is more widely expressed in breast cancer cells compared to of estrogen receptor-alpha (ER- $\alpha)$ (Nesaretnam et al., 2012). The MDA-MB-231 breast cancer cells express ER- $\beta$ (Comitato et al., 2009) whereas MCF7 breast cancer cells express both ER- $\alpha$ and ER- $\beta$ (Comitato et al., 2010). In silico simulations and in vitro competitive binding assays have shown that T3 have higher binding activity for ER- $\beta$ compared to ER- $\alpha$ (Comitato et al., 2010; 2009). In the present 
study, there was higher uptake of T3 by the MDAMB-231 cells compared to MCF-7 cells (Figure 3), which may be related to T3's selective affinity towards ER- $\beta$.

\section{CONCLUSION}

The findings from the current study show that $\mathrm{T} 3$ induced apoptosis in the two human breast cancer cells (MDA-MB-231 and MCF-7) through PARP-1 inactivation and down-regulation of COX-2. The extent of the apoptotic activity correlated with the rate of vitamin E uptake by these cancer cells.

\section{ACKNOWLEDGEMENT}

The authors would like to thank the DirectorGeneral of MPOB, for providing the research grant that supported this study. This work was supported by research grants from MPOB (Project ID: PD14209). Sincere acknowledgments to Ghazali Abd Razak for technical assistance in HPLC analysis.

\section{REFERENCES}

Aggarwal, B; Sundaram, C; Prasad, S and Kannappan, R (2010). Tocotrienols, the vitamin E of the $21^{\text {st }}$ century: Its potential against cancer and other chronic diseases. Biochem. Pharmacol., 80: 1613-1631.

Aggarwal, V; Kashyap, D; Sak, K; Tuli, H S; Jain, A; Chaudhary, A; Garg, V K; Sethi, G and Yerer, M B (2019). Molecular mechanisms of action of tocotrienols in cancer: Recent trends and advancements. Int. J. Mol. Sci., 20: 656-674.

Ahsan, H; Ahad, A; Iqbal, J and Siddiqui, W A (2014). Pharmacological potential of tocotrienols: A review. Nutr. Metab., 11: 1-22.

Begum, N and Terao, J (2002). Protective effect of $\alpha$-tocotrienol against free radical-induced impairment of erythrocyte deformability. Biosci. Biotech. Biochem., 66: 398-403.

Cavalcanti, É B; Félix, M B; Scotti, L and Scotti, M T (2019). Virtual screening of natural products to select compounds with potential anticancer activity. Anticancer Agents Med. Chem., 19: 154-171.

Chae, H-S; Xu, R; Won, J-Y; Chin, Y-W and Yim, H (2019). Molecular targets of genistein and its related flavonoids to exert anticancer effects. Int. J. Mol. Sci., 20: $2420-2438$.
Comitato, R; Leoni, G; Canali, R; Ambra, R; Nesaretnam, K and Virgili, F (2010). Tocotrienols activity in MCF-7 breast cancer cells: Involvement of ER $\beta$ signal transduction. Mol. Nutr. Food. Res., 54: 669-678.

Comitato, R; Nesaretnam, K; Leoni, G; Ambra, R; Canali, R; Bolli, A; Marino, M and Virgili, F (2009). A novel mechanism of natural vitamin $\mathrm{E}$ tocotrienol activity: Involvement of ER $\beta$ signal transduction. Am. J. Physiol. Endocrinol. Metab., 297: E427-E437.

Divvela, A K C; Challa, S R and Tagaram, I K (2010). Pathogenic role of Cyclooxygenase-2 in cancer. J. Health Sci., 56: 502-516.

Domagala, P; Huzarski, T; Lubinski, J; Gugala, K and Domagala, W (2011). PARP-1 expression in breast cancer including BRCA1-associated, triple negative and basal-like tumors: possible implications for PARP-1 inhibitor therapy. Breast Cancer Res. Treat., 127: 861-869.

Fu, J-Y; Maniam, G; Wong, F-S; Tan, D M-Y; Meganathan, P and Chuah, L-H (2019). Tocotrienols: From bench to bedside. InVitamin E: 12-31.

Fukui, K; Shirai, M; Ninuma, T and Kato, Y (2019). Anti-obesity effects of tocotrienols and bran in highfat diet-treated mice. Nutrients, 11: 830-842.

Hisham, A N and Yip, C H (2004). Overview of breast cancer in Malaysian women: A problem with late diagnosis. Asian J. Surg., 27: 130-133.

Howe, L R (2007). Cyclooxygenase/prostaglandin signaling and breast cancer. Breast Cancer Res. Treat., 9: 210-219.

Jahnavi, K; Reddy, P P; Vasudha, B and Narender, B (2019). Non-steroidal anti-inflammatory drugs: An overview. J. Drug Deliv. Ther., 9: 442-448.

Kotsopoulos, J; Metcalfe, K; Alston, J; Nikitina, D; Ginsburg, O; Eisen, A; Demsky, R; Akbari, M; Zbuk, $\mathrm{K}$ and Narod, S A (2014). Prospective study of highrisk, BRCA1/2-mutation negative women: The 'negative study'. BMC Cancer, 14: 221-231.

Lee, M-S; Ma'ruf, C A A; Izhar, D P N; Ishak, S N; Jamaluddin, WS W; Ya'acob, S N M and Kamaluddin, M N (2019). Awareness on breast cancer screening in Malaysia: A cross sectional study. BioMedicine, 9(3): 19-25.

Loganathan, R; Radhakrishnan, A K; Selvaduray, K R and Nesaretnam, K (2015). Selective anti-cancer effects of palm phytonutrients on human breast cancer cells. RSC Adv., 5: 1745-1753. 
Loganathan, R; Selvaduray, K R; Nesaretnam, $\mathrm{K}$ and Radhakrishnan, A K (2013). Tocotrienols promote apoptosis in human breast cancer cells by inducing poly(ADP-ribose) polymerase cleavage and inhibiting nuclear factor kappa-B activity. Cell Prolif., 46: 203-213.

Ma, X; Dang, C; Min, W; Diao, Y; Hui, W; Wang, X; Dai, Z; Wang, X and Kang, H (2019). Downregulation of APE1 potentiates breast cancer cells to olaparib by inhibiting PARP-1 expression. Breast Cancer Res. Treat., 176: 109-117.

Mcintyre, B S; Briski, K P; Gapor, A and Sylvester, P W (2000a). Antiproliferative and apoptotic effects of tocopherols and tocotrienols on preneoplastic and neoplastic mouse mammary epithelial cells. Proc. Soc. Exp. Biol. Med., 224: 292-301.

Mcintyre, B S; Briski, K P; Tirmenstein, M A; Fariss, M W; Gapor, A and Sylvester, P W (2000b). Antiproliferative and apoptotic effects of tocopherols and tocotrienols on normal mouse mammary epithelial cells. Lipids, 35: 171-180.

Montagnani Marelli, M; Marzagalli, M; Fontana, F; Raimondi, M; Moretti, R M and Limonta, P (2019). Anticancer properties of tocotrienols: A review of cellular mechanisms and molecular targets. J. Cell. Physio., 234: 1147-1164.

Nesaretnam, K; Meganathan, P; Veerasenan, S D and Selvaduray, K R (2012). Tocotrienols and breast cancer: The evidence to date. Genes Nutr., 7: 3-9.

Palozza, P; Verdecchia, S; Avanzi, L; Vertuani, S; Serini, S; Iannone, A and Manfredini, S (2006). Comparative antioxidant activity of tocotrienols and the novel chromanyl-polyisoprenyl molecule FeAox-6 in isolated membranes and intact cells. Mol. Cell Biochem., 287: 21-32.

Pinto, L; Sloan, A; Persaud, I and Narain, N R (2009). Normalization of BCL-2 family members in breast cancer by coenzyme Q10. Ethnicity and Disease, 19: 17-18.

Ricci, M S and Zong, W-X (2006). Chemotherapeutic approaches for targeting cell death pathways. Oncologist, 11: 342-357.

Satoh, T H; Surmacz, T A; Nyormoi, O and Whitacre, C M (2003). Inhibition of focal adhesion kinase by antisense oligonucleotides enhances the sensitivity of breast cancer cells to camptothecins. Biocell., 27: 47-55.
Sen, C K; Khanna, S; Roy, S and Packer, L (2000). Molecular basis of vitamin $\mathrm{E}$ action tocotrienol potently inhibits glutamate-induced pp60c-Src kinase activation and death of ht 4 neuronal cells. J. Biol. Chem., 275: 13049-13055.

Shirode, A B and Sylvester, P W (2010). Synergistic anticancer effects of combined gamma-tocotrienol and celecoxib treatment are associated with suppression in Akt and NFkappaB signaling. Biomed. Pharmacother., 64: 327-32.

Tung, Y-H and Ng, L-T (2019). Effects of nitrogen fertilization rate on tocopherols, tocotrienols and $\gamma$-oryzanol contents and enzymatic antioxidant activities in rice grains. Physio. Mol. Bio. Plants, 25: 189-195.

U.S. Food and Drug Administration (2009). Generally Recognized as Safe (GRAS) determination for the use of palm tocotrienol rich fractions (TRF) as ingredients in food. www.accessdata.fda.gov/ scripts / fcn/gras_notices/grn_307.pdf, accessed on 20 October 2012.

World Health Organisation (2018). Cancer. https: / / www.who.int/ news-room / fact-sheets / detail/cancer, accessed on 8 May 2019.

Wu, S-J; Liu, P-L and Ng, L-T (2008). Research article tocotrienol-rich fraction of palm oil exhibits anti-inflammatory property by suppressing the expression of inflammatory mediators in human monocytic cells. Mol. Nutr. Food Res., 52: 921-929.

Yam, M-L; Hafid, S R A; Cheng, H-M and Nesaretnam, K (2009). Tocotrienols suppress proinflammatory markers and cyclooxygenase-2 expression in RAW264. 7 macrophages. Lipids, 44: 787-797.

Yang, C and Jiang, Q (2019). Vitamin E $\delta$-tocotrienol inhibits TNF- $\alpha$-stimulated NF- $\kappa$ B activation by upregulation of anti-inflammatory A20 via modulation of sphingolipid including elevation of intracellular dihydroceramides. J. Nut. Biochem., 64: 101-109.

Yoshida, Y; Niki, E and Noguchi, N (2003). Comparative study on the action of tocopherols and tocotrienols as antioxidant: Chemical and physical effects. Chem. Phys. Lipids, 123: 63-75.

Zhang, Q; Bao, J and Yang, J (2019). Genisteintriggered anticancer activity against liver cancer cell line HepG2 involves ROS generation, mitochondrial apoptosis, G2/M cell cycle arrest and inhibition of cell migration. Arch. Med. Sci., 15: 1001-1011. 